\title{
Intraplate deformation in the Samoa-Gilbert-Ralik area: a prelude to a change of plate boundaries in the Southwest Pacific?
}

\author{
EMILE A. OKAL ${ }^{1}$, DALE F. WOODS ${ }^{1}$ and THORNE LAY ${ }^{2}$ \\ ${ }^{1}$ Department of Geological Sciences, Northwestern University, Evanston, IL 60201 (U.S.A.) \\ ${ }^{2}$ Department of Geological Sciences, University of Michigan, Ann Arbor, MI 48109 (U.S.A.)
}

(Received Decemher 26, 1985; accepted April 17, 1986)

\begin{abstract}
Okal, E.A., Woods, D.F. and Lay, T., 1986. Intraplate deformation in the Samoa-Gilbert-Ralik area: a prelude to a change of plate boundaries in the Southwest Pacific? In: B. Johnson and A.W. Bally (Editors), Intraplate Deformation: Characteristics, Processes and Causes. Tectonophysics, 132: 69-77.

Intense intraplate seismic activity has recently been identified in the west-central Pacific, along a line extending from Samoa through the Gilbert Islands and the Ralik Fracture Zone to the Caroline Islands. Over the past 50 years, this seismic line has contributed an estimated 15-30\% of the entire intraplate seismicity for the Pacific plate (Hawaii excepted). Focal mechanisms available for ten of the largest events during the 1981-1983 Gilbert Islands swarm, with horizontal compressional stress oriented at right angles to the direction of motion of the plate, cannot be reconciled with simple models of intraplate stresses. We speculate that they express large scale deformation of that part of the Pacific plate, related to incipient detachment of a microplate and relocation of the Pacific-Australian subduction zone some $1000 \mathrm{~km}$ to the north of its present position.
\end{abstract}

\section{Introduction}

Over the past 15 years, the theory of plate tectonics has met with great success in explaining large-scale geodynamical processes at the surface of the Earth. In doing so, most studies have relied on the concept of a system of plates and boundaries, with essentially steady-state kinematic characteristics (rates and directions of slip, accretion, or subduction) over time periods of at least several million years. A typical example would be the Mid-Atlantic Ridge, from the Charlie-Gibbs Fracture Zone to the Bouvet triple junction, whose rate of accretion and orientation have not changed significantly in the past $50 \mathrm{Ma}$.

However, at the same time, our steadily improving knowledge of the forces driving the plates has identified conditions under which plate motions must change; in particular, light material, which can be either continental or very young oceanic crust, cannot subduct under its own weight, and when reaching an active subduction zone, forces cessation of subduction, and subsequent rearrangement of the plates' kinematics. A classic example is the Cenozoic collision of the Farallon Ridge with the West American subduction zone, as described by Atwater (1970). In this paper, we analyze a line of intense seismic activity along the southern flank of the Pacific plate, and speculate that the corresponding deformation may represent the early stages of a reorganization of the Australia-Pacific subduction zones, due to imminent collision of unsubductible material with the trenches. 


\section{Seismicity along the Samoa-Ralik line}

The area centered around the Gilbert Islands has been the site of intense intraplate seismic activity, with three different seismic regions recently identified (see Fig. 1).

\section{Gilbert Islands}

During the period 1981-1983, a large swarm of 224 teleseismically recorded earthquakes (with magnitudes $m_{\mathrm{b}}=4.0-6.0$ ) took place at the southern end of the Gilbert Islands chain in an area where no previous activity was known. The history of the swarm is shown on Fig. 2. In a previous study (Lay and Okal, 1983; hereafter Paper I), we analyzed in detail the mechanism of four of the largest events in the swarm and reached the following conclusions:

(1) The four earthquakes share a common horizontal axis of compression, oriented $\mathrm{N} 20 \pm$ $10^{\circ} \mathrm{E}$ (see Fig. 3 and Table 1). Three out of the four earthquakes share an almost identical thrust fault mechanism, the fourth one has a strike-slip mechanism with the same horizontal compressional axis as the thrust events; body-wave modelling indicates that the fourth earthquake is also deeper: $21 \mathrm{~km}$ vs. $15 \mathrm{~km}$. This change of the nature of faulting with depth simply illustrates the effect of the lithostatic pressure on the ambient

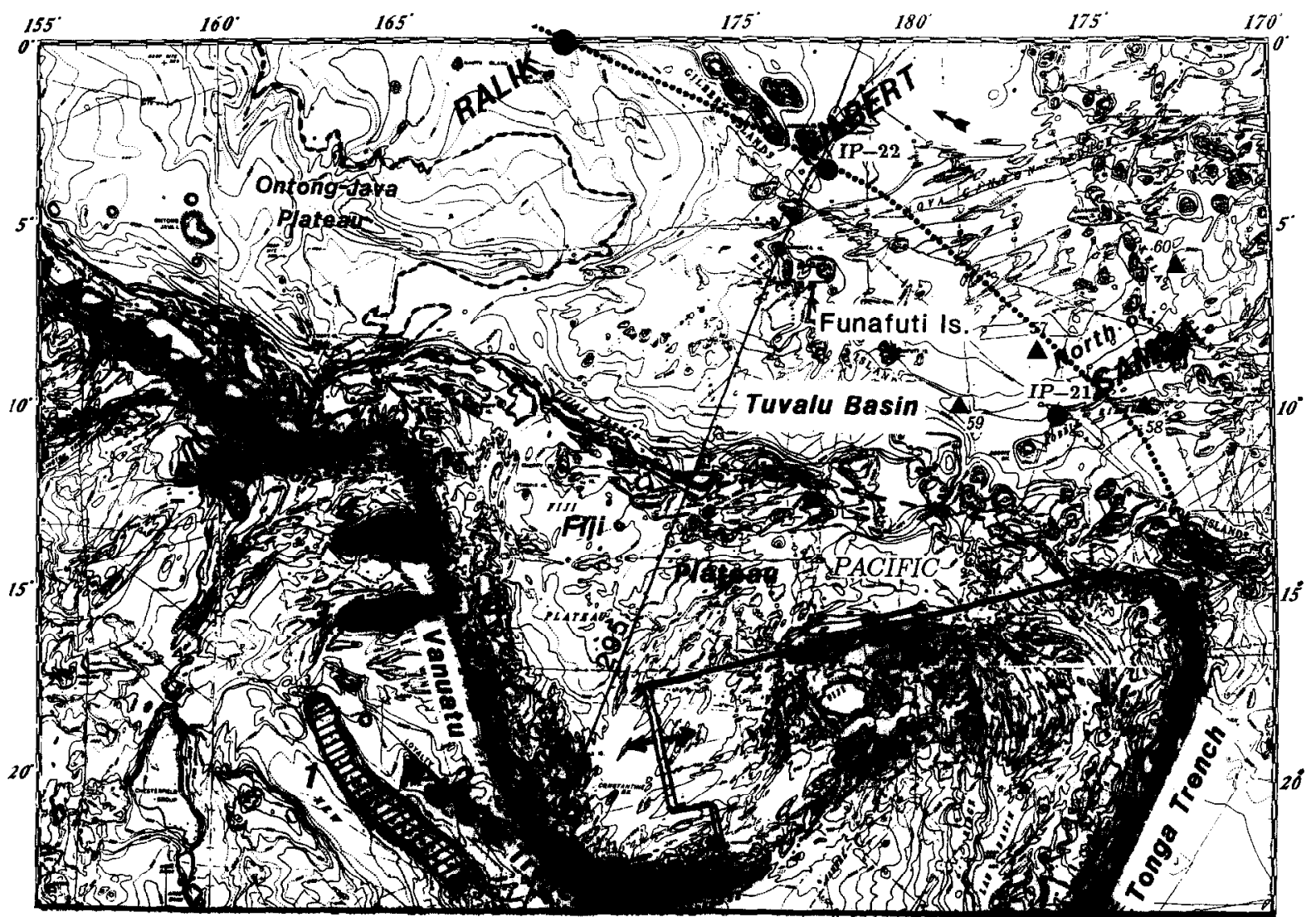

Fig. 1. Map of the Ralik-Gilbert Islands-Samoa area, adapted from Mammerickx et al. (1975). Relevant intraplate seismicity shown as individual dots (precise or relocated epicenters), and triangles (reported locations of pre-1964 earthquakes; see Okal, 1984, for details). Thick lines are plate boundaries (after Chase, 1971, in Fiji area). The arrow next to the Gilbert epicenter identifies the direction of plate motion, and hence of the expected ridge-push. The dotted line identifies the line of intraplate seismicity which may become the new plate boundary. The hatched areas in the Australian plate identify the buoyant, unsubductible blocks: (1) New Caledonia; (2) Loyalty Islands; (3) d'Entrecasteaux Ridge; (4) Torres Rise; and (5) Rennell Island and Indispensible Reefs. The dashed lines, following approximately the 2000 -fathom contour, identify the two buoyant features in the Pacific plate (Ontong-Java and Fiji plateaux). The path of SEASAT track 295, plotted on Fig. 4, is also shown. 


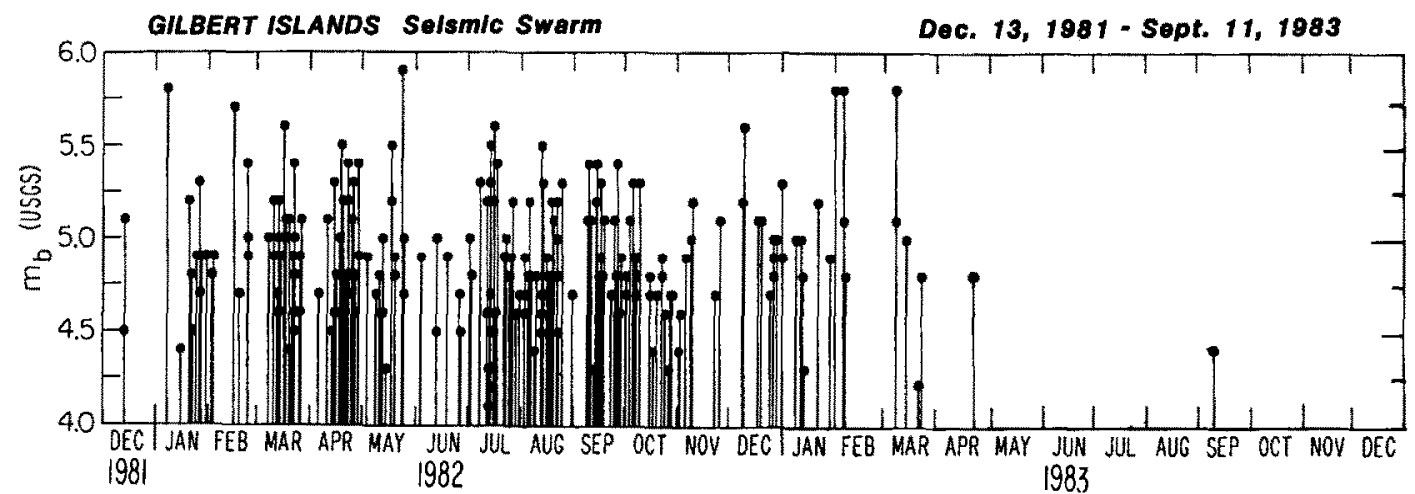

Fig. 2. Complete history of Gilbert Islands swarm, Dec., 1981-Sept., 1983. Note abrupt termination of the swarm; the absence of any known seismicity prior to December, 1981 also shows very abrupt initiation.

stress conditions, and has been reported elsewhere in oceanic plates (Wiens and Stein, 1984; Bratt et al., 1985).

(2) A frequency-magnitude ( $b$-value) investigation of the swarm yielded $b=1.35$, clearly on the high side of the range of values computed for worldwide catalogues of intraplate oceanic seismicity (Okal, 1983), but not significantly higher than found (1.32) by Bergman and Solomon (1980) for a 15-year dataset of Pacific intraplate earthquakes.

(3) Mesozoic magnetic anomalies in this part of the Pacific feature an offset defining a small fracture zone, whose extrapolation runs through the epicentral area, suggesting a possible zone of weakness and preferential seismic energy release. They also indicate an age of approximately 115 Ma for the lithosphere in the area (Larson and Chase, 1972).

Since Paper I was published, focal mechanisms for six additional earthquakes of the swarm were published in the Monthly Bulletins of the U.S. Geological Survey's Preliminary Determination of Epicenters (PDE). Despite the tentative character of these results, involving earthquakes of generally lower magnitudes, Table 1 shows clearly that the ten events form a homogeneous dataset, whose average compressional axis is shallow dipping and oriented $\mathrm{N} 22^{\circ} \mathrm{E}$, with a standard deviation of only

\section{TABLE 1}

Focal mechanisms and stress axes for Gilbert Islands events

\begin{tabular}{|c|c|c|c|c|c|c|c|c|}
\hline \multirow{2}{*}{$\begin{array}{l}\text { Date } \\
\text { yr. m.d. }\end{array}$} & \multicolumn{3}{|c|}{ Fault plane } & \multicolumn{2}{|l|}{$P$-axis } & \multicolumn{2}{|l|}{$T$-axis } & \multirow{2}{*}{$\begin{array}{l}\text { Moment } \\
\left(10^{25} \mathrm{dyn} \mathrm{cm}\right)\end{array}$} \\
\hline & $\begin{array}{l}\phi \\
\left({ }^{\circ}\right)\end{array}$ & $\begin{array}{l}\delta \\
\left({ }^{\circ}\right)\end{array}$ & $\begin{array}{l}\lambda \\
\left({ }^{\circ}\right)\end{array}$ & $\begin{array}{l}\text { plunge } \\
\left({ }^{\circ}\right) \\
\end{array}$ & $\begin{array}{l}\text { azimuth } \\
\left({ }^{\circ}\right)\end{array}$ & $\begin{array}{l}\text { plunge } \\
\left({ }^{\circ}\right)\end{array}$ & $\begin{array}{l}\text { azimuth } \\
\left({ }^{\circ}\right)\end{array}$ & \\
\hline \multicolumn{9}{|c|}{ Lay and Okal (1983) solutions } \\
\hline 19820107 & 125 & 60 & 120 & 10 & 194 & 62 & 84 & 1.0 \\
\hline 19820215 & 253 & 86 & 0 & 3 & 208 & 3 & 118 & 1.5 \\
\hline 19820316 & 140 & 60 & 138 & 3 & 198 & 50 & 104 & 1.0 \\
\hline 19820523 & 120 & 54 & 120 & 5 & 189 & 66 & 89 & 0.7 \\
\hline \multicolumn{9}{|c|}{ Harvard solutions for other events } \\
\hline 19820418 & 121 & 16 & 95 & 29 & 27 & 61 & 204 & 0.12 \\
\hline 19820713 & 113 & 58 & 87 & 13 & 205 & 77 & 14 & 0.10 \\
\hline 19820715 & 136 & 75 & 111 & 27 & 209 & 55 & 72 & 0.10 \\
\hline 19821209 & 124 & 42 & 114 & 5 & 17 & 73 & 125 & 0.16 \\
\hline 19830131 & 121 & 53 & 101 & 7 & 203 & 78 & 74 & 0.19 \\
\hline 19830205 & 130 & 36 & 95 & 9 & 36 & 80 & 198 & 0.19 \\
\hline 19830308 & 118 & 27 & 96 & 18 & 24 & 72 & 194 & 0.12 \\
\hline
\end{tabular}




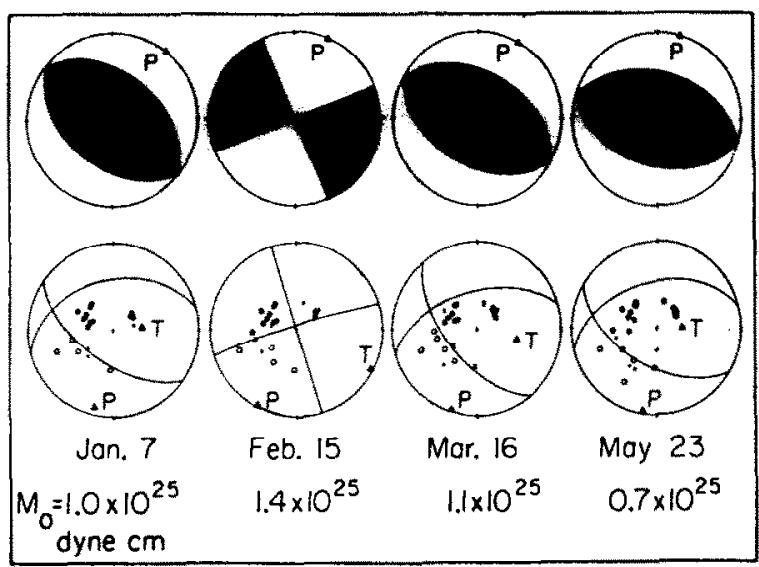

Fig. 3. Summary of the focal mechanisms and moment determinations for the four largest events of the Gilbert Islands swarm (Lay and Okal, 1983). The top row shows the orientation of the major double-couple found by constrained moment tensor inversion of surface waves; the bottom are mechanisms constrained by body-waves. Note the consistent orientation of the compressional (P) axes.

$8^{\circ}$. Eight events are thrust faults striking $118^{\circ}$ $140^{\circ}$, and the other two strike-slip faults striking about $250^{\circ}$. There is some suggestion from the PDE data that the strike-slip event on January 31, 1983 may be somewhat deeper than the rest ( 31 $\mathrm{km})$.

As part of their systematic compilation of earthquake focal mechanisms, Dziewonski et al. (1983) have shown that some Gilbert Islands events, in particular the one on May 23, 1982, are among the few worldwide earthquakes for which moment-tensor inversion of seismic waves yields a significant second double-couple, i.e., whose seismic source departs from the simple model of rupture along a fault plane. On a much larger scale (with the non-double couple component reaching $50 \%$ of the seismic moment, vs. $\sim 20 \%$ for the Gilbert event), similar characteristics have been claimed in earthquakes believed to involve volcanic phenomena (e.g., the Mammoth Lakes 1980 sequence (Julian and Sipkin, 1985), although Wallace (1985) has questioned such observations). On this basis, and bearing in mind the somewhat higher than usual $b$-value, one could advocate that the Gilbert Islands swarm was due to a major submarine volcano-seismic event. On the other

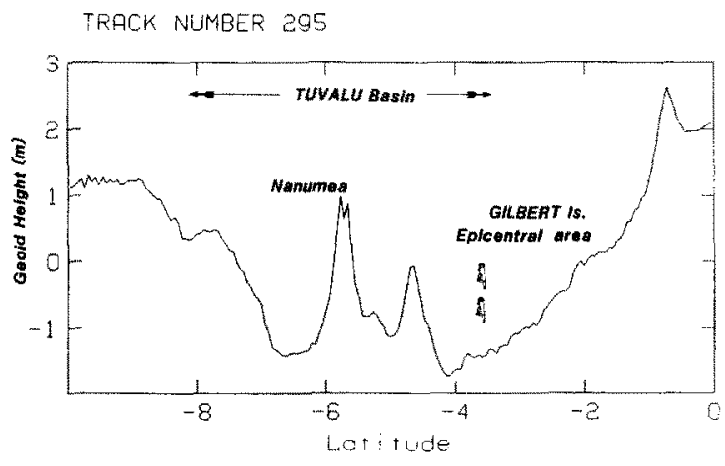

Fig. 4. SEASAT track Number 295 in the area of the Gilbert Islands. The degree-10 geoid has been removed, as well as the linear trend over this section of track. Note (1) absence of signature in epicentral area: (2) $2-3 \mathrm{~m}$ low in geoid in the Tuvalu Basin; and (3) signature of Nanumea (Tuvalu, ex-Ellice Islands).

hand, the following evidence argues strongly against volcanic origin:

(a) The absence of any record of documented recent volcanism in this part of the world.

(b) The absence of any significant bathymetric signal in the local SEASAT geoid, as would be created by an uncharted volcanic seamount structure (see Fig. 4).

(c) The generally high level of the seismicity, estimated to involve a cumulative moment of $10^{26}$ dyn $\mathrm{cm}$.

(d) The coherence in the direction of compressional stress released in the events, as opposed to the many examples of normal faulting and extension tectonics involved during documented episodes of volcano-seismic activity (Kaufman and Burdick, 1980; Farmer et al., 1982).

On this basis, we prefer to assign the Gilbert Islands earthquake swarm to the release of compressional stress directed horizontally at an azimuth of $\mathrm{N} 22^{\circ} \mathrm{E}$. The origin of this stress itself is not explained in the framework of simple platetectonics theories. In particular, it is oriented approximately at right angles to the direction of the gravitational sliding force generally referred to as "ridge-push" (Turcotte and Schubert, 1982), and known to be the major contributor to intraplate stresses in older parts of oceanic plates (Bergman and Solomon, 1980; Okal, 1983; Wiens and Stein, 1985). 
As part of a general investigation of the intraplate seismicity of the southern part of the Pacific plate, Okal (1984) has identified five earthquakes in the area north of Samoa (and approximately $1000 \mathrm{~km}$ to the southeast of the Gilbert swarm epicenter; Fig. 1). Although the initial locations of these earthquakes (which occurred between 1937 and 1964) has poor accuracy, at least one of them is well located (1964), and our relocation efforts for the large 1937 event have failed to associate it with the nearby plate boundary. Low-level intraplate seismicity is also known in the immediate vicinity of Samoa.

\section{Ralik fracture zone area}

In addition, Walker and McCreery $(1984,1985)$ have recently identified a seismic epicenter with three events during 1983 , at $0^{\circ} \mathrm{N}$ and $170.0^{\circ} \mathrm{E}$ (see Fig. 1). These events were detected through their long-distance oceanic $P_{n}$ waves (the so-called " $P_{o}$ ") recorded on hydrophones at the Wake array. They have proposed to associate this seismic epicenter with the Ralik Fracture Zone, documented by Larson (1976) and Kroenke and Woodward (1984). More recently, Kroenke and Walker (1986) have reported seismicity near Kosrae $\left(5.5^{\circ} \mathrm{N}, 163.0^{\circ} \mathrm{E}\right)$ and in the vicinity of Ponape. These scientists have speculated that the magnitude of these earthquakes (as extrapolated from the high frequencies characteristic of $P_{o}$ ) could have exceeded 5.0, although detailed investigation of their waves on well-calibrated instruments suggests $m_{\mathrm{b}}=4.4$ at Warramunga and $M_{\mathrm{s}}=4.7$ at Alice Springs for the largest of these events (Muirhead and Adams, 1986).

Thus, the emerging pattern for the seismicity of the west-central Pacific, as shown on Fig. 1, would define a Samoa-Gilbert-Ralik line of preferential seismicity, along which a tentative total seismic moment budget for the years $1937-1983$ is 1 to $2 \times 10^{26} \mathrm{dyn} \mathrm{cm}$, or $15-30 \%$ of the entire intraplate seismicity for the Pacific plate (Hawaii excepted: Okal, 1984).

\section{A possible model}

It is tempting to envision the seismic line as expressing significant internal deformation of the southern "underbelly" of the Pacific plate, at a distance of $1000-1500 \mathrm{~km}$ north of the actual plate boundary. Of particular interest is the nature of the material subducting at the Vanuatu (ex New Hebrides), Santa Cruz and Solomon trenches. This part of the Australian plate bears, from south to north: the Norfolk Ridge, New Caledonia and the Loyalty Islands; the d'Entrecasteaux Ridge system; the Torres Rise; and Rennell Island. The Norfolk Ridge and New Caledonia are interpreted as continental in nature (Lillie and Brothers, 1970; Molnar et al., 1975). The d'Entrecasteaux Ridge is an aseismic ridge associated with an old fracture zone; it has been proved buoyant, from Bouguer anomalies (Luyendyk et al., 1974) and the alteration of the characteristics of subduction earthquakes (Chung and Kanamori, 1980). The origin of Rennell Island and Torres Rise is unclear, but they are also believed to be buoyant (L.W. Kroenke, pers. commun., 1984). The Loyalty complex is presently less than $50 \mathrm{~km}$ from the trench, and the Torres Rise within $100 \mathrm{~km}$. Thus, the part of the Australian plate in immediate contact with the subduction zone contains a large amount of buoyant, non-subductible material; we interpret the compressional stress released during the Gilbert events as due to the congestion at the Vanuatu trench, which locally perturbs the stress field in the Pacific plate away from the gravity sliding "ridge-push".

Proceeding one step further, we note that the presence of unsubductible material at the Vanuatu trench makes this subduction system unstable in the long-term. A new, different system system will have to develop in the relatively near future. In order to accommodate the necessary change in the subduction pattern, one could envision a simple change in the polarity of the subduction; however, this is very unlikely, since it would require the subduction of such structures as the Ontong-Java Plateau and the Fiji Plateau, both of which are buoyant (Funumoto et al., 1970; Chase, 1971); indeed Halunen and Von Herzen (1973) have proposed that the inability of the Ontong-Java Plateau 
to subduct was responsible for a previous reversal of the polarity of the subduction in the Solomon Islands. Certainly, a structure such as the Ontong-Java Plateau prevents any present-day return to a regime of subduction of the Pacific plate under Australia.

It is therefore likely that the plate boundary presently located at the Vanuatu-Santa CruzSolomon trenches will have to jump north in the relatively near future, in search of "subductible" material. At present, we can only speculate on the time it will take to achieve this jump, and on the particular steps it may involve. One possible scenario would feature the carving out of a piece of the Pacific as a "Tuvalu" microplate, under which the Pacific would start subducting, and which could eventually become sutured to, or slow moving with respect to, the Australian plate. While subduction of Tuvalu below the Pacific cannot be ruled out in the short term, it is unlikely since material making up the Tuvalu microplate (e.g., the Fiji plateau) is more buoyant than the old Pacific lithosphere to the northeast. Similar processes probably have taken place both in the Philippine plate area, and in Northwestern New Guinea. The present-day line of seismic activity and compressional stress from Samoa through the Gilberts to Ralik is of course a prime candidate for the northern boundary of such a microplate. Its extrapolation further west would link up with the northern boundary of the Caroline plate, thus suggesting an eventual detachment of the Caroline plate, the Ontong-Java Plateau, and the Ellice Islands from the main body of the Pacific plate. Figure 5 is a schematic cross-section of this speculative model.

What makes the Samoa-Gilbert-Ralik line the possible locus of future subduction remains an open question: no large-scale feature is identified in either the geoid or the bathymetry; we simply note that this line provides the shortest path from the Samoa corner to the north of the major buoyant feature, the Ontong-Java Plateau.

In a recent contribution, Kroenke and Walker (1986) have independently used a similar model to propose the existence of active subduction from Samoa to Yap along a possible "Micronesian" trench.

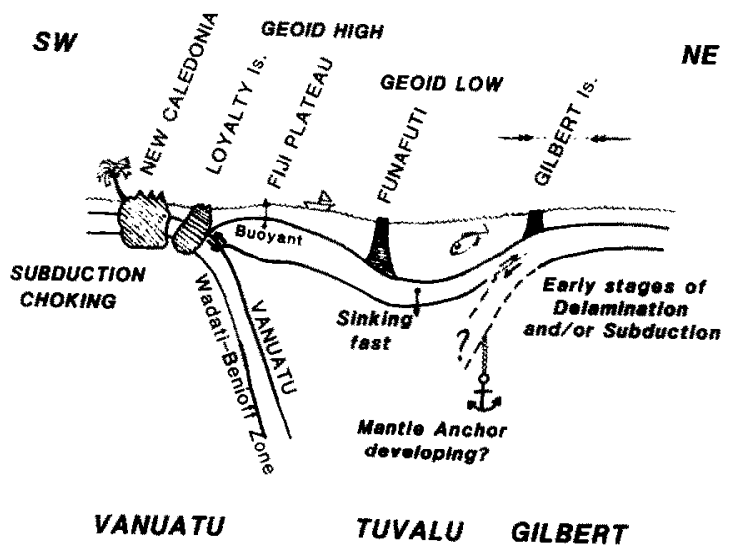

Fig. 5. Cartoon summarizing possible development of new plate boundary in Vanuatu-Tuvalu-Gilbert Islands area.

\section{Discussion and conclusion}

As mentioned above, a similar process of plate boundary re-arrangement probably was involved (and may still be taking place) in northwestern New Guinea. An earlier study of historical seismicity in that region (Okal et al., 1983) has shown that the line of most active seismicity (running along the northern coast of the island and generally interpreted as the plate boundary between the Australian and Caroline plates) features mostly large strike-slip earthquakes and thus is not representative of the convergence known to exist between Australia and the Pacific plate. In order to test whether a similar discrepancy exists in the Vanuatu-Solomon area, we computed composite slip vectors for both the Vanuatu and Solomon subduction zones from eighteen published moment tensor solutions in the area. The directions of convergence predicted by Minster and Jordan's (1978) kinematic model of plate motions are $\mathrm{N} 85^{\circ} \mathrm{E}$ at the Vanuatu trench, and $\mathrm{N} 82^{\circ} \mathrm{E}$ in the Solomon Islands. These values lie within the range of our composite slip vectors (azimuth $\mathrm{N} 80^{\circ} \mathrm{E} \pm 12^{\circ}$ for Vanuatu and $\mathrm{N} 86^{\circ} \mathrm{E} \pm 25^{\circ}$ for the Solomon trench). The limited dataset may be introducing systematic errors, which could be alleviated by generation of additional slip vectors; however, we must conclude that contrary to the case of New Guinea, the plate boundary at the Vanuatu and Solomon trenches does not (maybe not yet) exhibit unexpected focal mechanisms. In 
other words, the seismicity found along the Samoa-Gilbert-Ralik line does not (yet) take up a significant fraction of plate motion. This may explain the $50^{\circ}$ azimuth difference in velocity space between the direction of horizontal stress released at the Gilbert Islands site (possibly representing the future Tuvalu-Pacific motion) and the relative motion between Australia and the Pacific (or Australia-Tuvalu).

In general, other geophysical data are compatible with the suggestion of incipient subduction: geoid anomalies in the area of the proposed microplate, as recorded by SEASAT radar altimetry, reveal that the general area of the Tuvalu (exEllice) Islands and Basin is clearly a relative low in the geoid (see Fig. 4; also Francheteau, 1983, and A., Cazenave, pers. commun., 1984), which may be a confirmation of the accelerated subsidence suggested by the very large carbonate growth rates on Funafuti (e.g., Schlanger et al., 1963; p. 1004).

It is important, however, to note a significant difference with mature subduction zones. In a well-developed subduction zone, such as Tonga, the low in the geoid occurs above the trench; if anything, it can be displaced at most $40 \mathrm{~km}$ towards the fore-arc basin, due to sediment accumulation (Cazenave et al., 1986), which anyway would not be expected in a developing system. In the case of the Gilbert Islands, one would expect the trench to develop in the vicinity of the seismic line; on the other hand, the low in the geoid is spread over the entire Tuvalu Basin, a width of over $400 \mathrm{~km}$. Thus the geoid signature in the area of Tuvalu and the Gilbert Islands is not that of a trench, and certainly cannot be used to prove active subduction; it may, however, be related to subsidence that eventually leads to incipient subduction.

The level of seismicity along the Samoa-Gilbert-Ralik line does not reach magnitude 6 . This, and the failure of slip vectors at the Vanuatu trench to depart significantly from the predicted direction of Pacific-Australia motion, are fundamental differences with the case of the Indian Ocean, where Wiens et al. $(1985,1986)$ have proposed the model of a diffuse plate boundary (between India-Arabia and Australia) taking up sig- nificant convergence $(\sim 1 \mathrm{~cm} / \mathrm{yr})$ as a preliminary step towards the relocation of a subduction zone south of India.

A speculative scenario for the change of plate boundary patterns due to the "choking" of a subduction zone on buoyant material could be as follows:

(1) Development of intraplate stresses, buckling of overriding plate and initiation of subduction. This is presently the case in the Gilbert Islands area.

(2) Transfer of a significant amount of plate convergence to the new boundary, which remains a diffuse feature as long as the relative motion does not exceed $1.5 \mathrm{~cm} / \mathrm{yr}$. This is, however, sufficient to result in large earthquakes $(M \geq 6)$, and allow resolution of a system of two plates in kinematic models. A present example is the situation in the central Indian Ocean;

(3) Development of a small microplate between two well-defined subduction zones, possibly of opposite polarities. This is presently the case in the Banda Sea and the Molucca Sea areas. An alternative can be the evolution of the doomed subduction zone into a passive boundary (strikeslip), and the relocation of only the convergent component of the plate motion to the new plate boundary (an example being the situation in present-day Northwestern New Guinea); or the plate pattern can be drastically changed through a large-scale readjustment (as in the case of the San Andreas system).

(4) Finally, the original subduction ceases and the microplate is welded to the unsubductible material.

We want to stress the fundamentally speculative nature of our model calling for plate rearrangement and incipient subduction in the Southwestern Pacific. In particular, we do not want to speculate further about the duration of the various episodes of readjustment. The last process (welding) could be expected to last at least $10^{7}$ years, given the buoyant character of the microplate reflecting a hot thermal state, and hence the increased probability of enhanced deformation and significant orogeny.

In conclusion, our model provides an attractive possible explanation of the unusual seismicity in 
the area, and could be tested through additional geophysical exploration and investigations in the area.

\section{Acknowledgments}

The original work on the Gilbert Islands swarm benefited from discussions with Hiroo Kanamori and Terry Wallace. The SEASAT data were obtained and analyzed in collaboration with Anny Cazenave. The present ideas owe much to discussion and exchange of data with Loren Kroenke and Dan Walker, during a visit of the first author to the Hawaii Institute of Geophysics in December 1984; finally, the Texas A \& M Symposium provided an ideal forum for the discussion and refinement of the proposed model. Careful reviews by Seth Stein and Brann Johnson contributed to improving the manuscript. Partial support of this research by the National Science Foundation, under Grants EAR-83-05847 and EAR-84-05040 is gratefully acknowledged. We also thank the Donors of the Petroleum Research Fund, administered by the American Chemical Society, for support of this research under Grant Number PRF17294-AC2.

\section{References}

Atwater, T., 1970. Implications of plate tectonics for the Cenozoic tectonic evolution of western North America. Geol. Soc. Am. Bull., 81: 3513-3536.

Bergman, E.A and Solomon, S.C., 1980. Oceanic intraplate earthquakes: implications for local and regional intraplate stress. J. Geophys. Res., 85: 5389-5410.

Bratt, S.R., Bergman, E.A. and Solomon, S.C., 1985. Thermoelastic stress: how important as a cause of carthquakes in young oceanic lithosphere? J. Geophys. Res., 90: 10249-10260.

Cazenave, A., Rosemberg-Borot, C. and Rabinowicz, M., 1986. Geoid lows over deep-sea trenches. J. Geophys. Res., 91 1989-2003.

Chase, C.G., 1971. Tectonic history of the Fiji Plateau. Geol. Soc. Am. Bull., 82: 3087-3110.

Chung, W.-Y. and Kanamori, H., 1980. Subduction process of a fracture zone and aseismic ridges-the focal mechanism and source characteristics of the New Hebrides earthquake of 1969 January 19 and some related events. Geophys. J. Roy. Astron. Soc., 54: 221-240.

Dziewonski, A.M., Friedman, A., Giardini, D. and Woodhouse, J.H., 1983. Global seismicity of 1982: centroid-mo- ment tensor solutions for 308 earthquakes. Phys. Earth Planet Inter., 33: 76-90.

Farmer, R.A., Fujita, K. and Stein, S., 1982. Seismicity and tectonics of the Scotia Sea area (abstr.), Eos, Trans. Am. Geophys. Union, 63: 440.

Francheteau, J., 1983. The oceanic crust. Sci. Am., 249(3): 114-129.

Furumoto, A.S., Hussong, D.M., Campbell, J.F., Sutton, G.H., Malahoff, A., Rose, J.C. and Woollard, G.P.. 1970. Crustal and upper mantle structure of the Solomon Islands as revealed by seismic refraction of November-December 1966 . Pac. Sci., 24: 315-332.

Halunen, A.J., Jr. and Von Herzen, R.P., 1973. Heat flow in the western equatorial Pacific Ocean. J. Geophys. Res., 78: 5195-5208.

Julian, B.R. and Sipkin, S.A., 1985. Earthquake processes in the Long Valley Caldera, California. J. Geophys. Res., 90: 11155-11169.

Kaufman, K. and Burdick L.J., 1980. The reproducing earthquakes of the Galápagos Islands. Bull. Seismol. Soc. Am., 70: $1759-1770$.

Kroenke, L.W, and Walker, D.A., 1986. Evidence for the formation of a new trench in the Western Pacific. Eos, Trans. Am. Geophys. Union. 67: 145-146.

Kroenke, L.W. and Woodward, P., 1984. Tectonic elements of the Southwest Pacific. In: Geophysical Atlas of the Southwest Pacific. CCOP/SOPAC, Suva, Fiji.

Larson, R.L., 1976. Late Jurassic and Early Cretaceous evolution of the western central Pacific Ocean. I. Geomagn. Geoelectr., 28: 219-236.

Larson, R.L. and Chase, C.G., 1972. Late Mesozoic evolution of the western Pacific Ocean. Geol. Soc. Am. Bull., 83: 3627-3644.

Lay, T. and Okal, E.A., 1983. The Gilbert Islands (Republic of Kiribati) earthquake swarm of 1981-1983. Phys. Earth Planet. Inter., 33: 284-303.

Lillie, A.R. and Brothers, R.N, 1970. The geology of New Caledonia, N.Z. J. Geol. Geophys, 13: 145-183.

Luyendyk, B.P., Bryan, W.B. and Jezek, P.A., 1974. Shallow structure of the New Hebrides island arc. Geol. Soc. Am. Bull, 85: 1287-1300.

Mammerickx, J., Smith, S.M., Taylor, I.L. and Chase, T.E., 1975. Bathymetry of the South Pacific (Map). IMR Tech. Rep. Ser. TR 56, Scripps Inst. Oceanogr.. Univ. of Calif., San Diego.

Minster, J,B. and Jordan, T.H., 1978. Present-day plate motions. J. Geophys. Res., 83: 5331-5354.

Molnar, P., Atwater, T., Mammerickx, J. and Smith, S.M., 1975. Magnetic anomalies, bathymetry, and the tectonic evolution of the South Pacific since the Late Cretaceous. Geophys. J. R. Astron. Soc., 40: 383-420.

Muirhead, K. and Adams, R.D., 1986. Earthquakes in the "aseismic" regions of the Western Pacific. Geophys. Res. Lett., 13: 169-172.

Okal, E.A., 1983. Oceanic intraplate seismicity. Annu. Rev, Earth Planet. Sci., 11: 195-214. 
Okal, E.A.. 1984. Intraplate seismicity of the southern part of the Pacific plate. J. Geophys. Res., 89: 10053-10071.

Okal, E.A., Heineman, M. and Grall, H., 1983. Tectonic implications of the seismicity of northwestern New Guinea. 1910-1979 (abstr.). Eos, Trans. Am. Geophys. Union, 64: 265.

Schlanger, S.O., Graf, D.L., Goldsmith, J.R., Macdonald, G.A., Sackett, W.M. and Potratz, H.A., 1963. Subsurface geology of Eniwetok Atoll. U.S. Geol. Surv. Prof. Pap., 260-BB: 991-1066.

Turcotte, D.L. and Schubert, G., 1982. Geodynamics. Wiley, New York, N.Y., 450 pp.

Walker, D.A. and McCreery, C.S., 1984. OPA, Newsletter of the Ocean P Alliance. Univ. Hawaii, Honolulu. 15 November 1984 .

Walker, D.A. and McCreery, C.S., 1985. Significant unreported earthquakes in "aseismic" regions of the Western Pacific. Geophys. Res. Lett., 12: 433-436.
Wallace, T.C., 1985. A re-examination of the moment tensor solutions of the 1980 Mammoth Lakes earthquakes. J. Geophys. Res., 90: 11171-11176.

Wiens, D.A. and Stein. S., 1984. Intraplate seismicity and stresses in young oceanic lithosphere. J. Geophys. Res., 89: 11442-11464.

Wiens, D.A. and Stein, S., 1985. Implications of oceanic intraplate seismicity for plate stresses, driving forces and rheology. Tectonophysics, 116: 143-162.

Wiens, D.A., DeMets, D.C., Gordon, R.G., Stein, S., Argus, D.F., Engeln, J.F., Lundgren, P.R., Quible, D., Stein, C.A., Weinstein, S. and Woods, D.F., 1985. A diffuse plate boundary model for Indian Ocean tectonics. Geophys. Res. Lett., 12: 429-432.

Wiens, D.A., Stein, S., DeMets, D.C., Gordon, R.G. and Stein, C.A., 1986. Plate tectonic models for Indian Ocean "intraplate" deformation. Tectonophysics, 132 (this volume): $37-48$. 